\title{
(C) OPEN ACCESS \\ Closing the mortality gap after a myocardial infarction in people with and without chronic obstructive pulmonary disease
}

\author{
Kieran J Rothnie, ${ }^{1}$ Liam Smeeth, ${ }^{1,2}$ Emily Herrett, ${ }^{1}$ Neil Pearce, ${ }^{1}$ Harry Hemingway, ${ }^{2,3}$ \\ Jadwiga Wedzicha, ${ }^{4}$ Adam Timmis, ${ }^{2,5}$ Jennifer K Quint ${ }^{1}$
}

- Additional material is published online only. To view please visit the journal online (http://dx.doi.org/10.1136/ heartjnl-2014-307251).

For numbered affiliations see end of article.

\section{Correspondence to} Kieran J Rothnie, Faculty of Epidemiology and Population Health, London School of Hygiene and Tropical Medicine, Keppel Street, London WC1E 7HT, UK; Kieran.Rothnie@ Ishtm.ac.uk

Received 27 November 2014 Revised 26 January 2015 Accepted 13 February 2015 Published Online First 12 March 2015

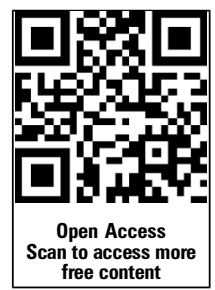

\section{SLinked}

- http://dx.doi.org/10.1136/ heartjnl-2015-307739

\section{CrossMark}

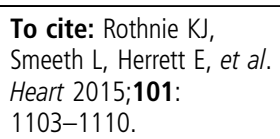

\section{ABSTRACT}

Objective Patients with chronic obstructive pulmonary disease (COPD) have increased mortality following myocardial infarction (MI) compared with patients without COPD. We investigated the extent to which differences in recognition and management after $\mathrm{Ml}$ could explain the mortality difference.

Methods 300161 patients with a first Ml between 2003 and 2013 were identified in the UK Myocardial Ischaemia National Audit Project database. Logistic regression was used to compare mortality in hospital and at 180 days postdischarge between patients with and without COPD. Variables relating to inhospital factors (delay in diagnosis, use of reperfusion and time to reperfusion/use of angiography) and use of secondary prevention were sequentially added to models.

Results Mortality was higher for patients with COPD both inhospital (4.6\% vs 3.2\%) and at 180 days ( $12.8 \%$ vs $7.7 \%)$. After adjusting for inhospital factors, the effect of COPD on inhospital mortality after MI was reduced for both ST-elevation myocardial infarctions (STEMIs) and non-STEMIs (STEMIs OR 1.24 (95\% Cl 1.10 to 1.41 ) to 1.13 (95\% Cl 0.99 to 1.29$)$; non-STEMIs OR 1.34 (95\% Cl 1.24 to 1.45$)$ to $1.16(95 \% \mathrm{Cl} 1.07$ to 1.26$))$. Adjusting for inhospital factors reduced the effect of COPD on mortality after non-STEMI at 180 days (OR 1.56 (95\% Cl 1.47 to 1.65 ) to 1.37 (95\% Cl 1.31 to 1.44$)$ ). Adjusting for use of secondary prevention also reduced the effect of COPD on mortality at 180 days for STEMls and non-STEMIs (STEMIs OR 1.45 (95\% CI 1.31 to 1.61) to $1.25(95 \% \mathrm{Cl} 1.11$ to 1.41$)$; non-STEMIs OR 1.37 ( $95 \% \mathrm{Cl} 1.31$ to 1.44 ) to 1.26 (95\% Cl 1.17 to 1.35$)$. Conclusions Delayed diagnosis, timing and use of reperfusion of a STEMI, use of angiography after a nonSTEMI and use of secondary prevention medicines are all potential explanations for the mortality gap after MI in people with COPD.

\section{INTRODUCTION}

People with chronic obstructive pulmonary disease (COPD) are at higher risk of cardiovascular disease $^{12}$ and are known to have poorer medium and longer-term outcomes after myocardial infarction (MI) compared with people without COPD, however, findings for inhospital mortality have been mixed. ${ }^{3-6}$ The heterogeneity in findings on inhospital mortality may be due to differences in treatment practices. COPD is currently the third leading cause of death worldwide. ${ }^{7}$ As up to one-third of deaths in people with COPD are due to cardiovascular disease, ${ }^{8}$ reducing deaths after MI in this population is important. In addition, there is a lack of evidence for the effectiveness of treatments in those with comorbidities.

Recent years have seen improvements in outcomes for patients after MI. ${ }^{9}$ However, several recent studies have continued to report poorer mortality for patients with COPD after an MI. Although the reasons for increased mortality after MI in patients with COPD are likely to include biological factors related to COPD, differences in recognition and management between patients with and without COPD may play a role. Recent work has demonstrated that patients with COPD are less likely to receive reperfusion treatment or $\beta$ blockers after an $\mathrm{MI},{ }^{10}$ and that not prescribing $\beta$ blockers to patients with COPD impacts on mortality. ${ }^{11}$

Little is known about potential differences in prescribing of other secondary prevention medicines, inhospital treatment or on the effects that any differences in these potentially modifiable factors may have on mortality.

We used Myocardial Ischaemia National Audit Project (MINAP), a national register of hospital care for acute coronary syndromes (ACS), to investigate the extent to which differences in recognition and management of an MI might account for the mortality gap in patients with COPD at the population level.

\section{METHODS}

\section{Data source}

The MINAP database is a registry of all admissions for MI and other ACS to hospitals in the UK. The dataset includes information on patient demographics, comorbidities, drugs on admission, initial diagnosis, final diagnosis, inhospital drug treatment, timing of reperfusion therapies, inhospital outcome and drugs given on discharge. ${ }^{12}$

We included all patients with a first diagnosis of ST-elevation myocardial infarction (STEMI) from January 2003 to June 2013 or non-ST-elevation myocardial infarction (non-STEMI) from January 2004 to December 2012. Records were excluded if they did not have a patient unique identifier, if patients had missing values for presence of obstructive airway disease or smoking history or if Office of National Statistics (ONS) mortality data were missing. 


\section{Exposure identification}

The obstructive airway disease variable in MINAP does not differentiate between COPD and asthma. In order to identify patients with COPD for this analysis, a strategy was developed and tested in a subset of the data linked with data from the Clinical Practice Research Datalink (CPRD). CPRD is a large UK clinical database of primary care medical records which includes over 5.5 million active patients $(8 \%$ of the population). ${ }^{13}$ Around half of the CPRD records have been linked to the MINAP database through the CALIBER linkage scheme. ${ }^{14}$ Patients with COPD can be identified in CPRD through the use of validated diagnostic codes. Using this subset of linked data, we developed strategy for identifying COPD patients in MINAP using CPRD-identified COPD as a reference standard. In this subset of data, patients with COPD were identified using a combination of MINAP-recorded obstructive airway disease and a smoking history (ex or current smoker). This strategy resulted in adequate identification of patients with COPD in MINAP, with agreement of $90.9 \%$.

\section{Outcome definitions}

\section{Recognition and management}

Delay in diagnosis of MI, reperfusion after a STEMI, use of angiography in hospital after a non-STEMI and discharge on secondary prevention drugs were investigated. Two definitions of delay in diagnosis were investigated for patients with a final diagnosis of STEMI: (1) delay in diagnosis of definite STEMI (defined as those who did not have an initial diagnosis of definite STEMI) and (2) delay in diagnosis of ACS (defined as those whose initial diagnosis was not STEMI, probable MI or ACS). For those patients with a final diagnosis of non-STEMI, one definition for delay in diagnosis was investigated: delay in diagnosis of ACS (defined as those whose initial diagnosis was not STEMI, probable MI or ACS).

\section{Mortality outcomes}

The UK ONS collects data on all recorded deaths in England and Wales. MINAP is linked with ONS mortality data, which provides data on vital status at 180 days postdischarge. Mortality at 180 days postdischarge was assessed for those who survived until discharge.

\section{Statistical analysis}

Demographic and clinical characteristics were tabulated for patients with COPD and non-COPD patients. All analyses were stratified by type of MI (STEMI or non-STEMI). The models were adjusted for smoking status, age, sex and calendar year, comorbidities including prior angina, cerebrovascular disease, chronic kidney failure, diabetes, congestive heart failure, hypertension, hyperlipidaemia, peripheral vascular disease, previous percutaneous coronary intervention ( $\mathrm{PCI}$ ) and previous coronary artery bypass graft and cardiovascular drugs (ACE inhibitor or angiotensin receptor blocker, $\beta$ blocker, statin and thienopyridine) use on admission. Following the suggested practice for missing data in MINAP, ${ }^{15}$ missing values for comorbidities and drugs on admission were recoded to 'no'. Other variables were not recoded and analyses were conducted on the basis of complete case analysis. Data were analysed using Stata V.13.0.

Analysis was conducted in three parts:

1. Describing the problem: differences in mortality after MI

between patients with COPD and non-COPD patients

We compared crude proportions of patients with COPD dying inhospital and at 180 days postdischarge to patients without
COPD. We then used logistic regression to adjust the comparisons of mortality for possible confounders for age, sex, smoking status, calendar year, comorbidities and drugs used on arrival.

2. Possible inhospital explanations: differences in recognition and management after an MI between patients with COPD and non-COPD patients

For STEMIs, we investigated differences in delay in STEMI diagnosis, use of primary PCI ( $\mathrm{pPCI}$ ), use of thrombolysis, time to reperfusion from hospital admission and use of secondary prevention drugs on discharge. We investigated the impact of delay in diagnosis on time to reperfusion, and we assessed whether COPD modified this relationship. For non-STEMIs, we investigated delay in diagnosis of MI, use of angiography in hospital and use of secondary prevention drugs on discharge.

3. Accounting for differences in mortality after MI between patients with COPD and non-COPD patients in terms of hospital processes

In order to investigate to what extent differences in diagnosis and treatment of patients with COPD after an MI might account for differences in mortality, variables relating to inhospital processes investigated in (2) were sequentially added to mortality models created in (1) with reference to a directed acyclic graph (see online supplementary material). Attributable risk of death due to COPD following MI was calculated before and after adjustment for inhospital processes using the formula $(\mathrm{OR}-1) / \mathrm{OR} \times 100$.

\section{RESULTS}

\section{Characteristics of participants}

Of the 300146 patients with first MI identified over the period, $34027(11.3 \%)$ had COPD. The inclusion and exclusion of records in the MINAP database are detailed in figure 1. The characteristics of the patients included in the study are detailed in table 1 . Mortality was higher for patients with COPD both inhospital (4.6\% vs $3.2 \%)$ and at 180 days $(12.8 \%$ vs $7.7 \%)$.

\section{ST-elevation myocardial infarctions}

1. Describing the problem: differences in mortality after MI between patients with COPD and non-COPD patients

After adjusting for age, sex, smoking status, calendar year, comorbidities and drugs on arrival, mortality in patients with COPD was higher than non-COPD patients in hospital (OR $1.24,95 \%$ CI 1.10 to 1.41 ), and 180 days after discharge (OR $1.45,95 \%$ CI 1.33 to 1.59 ).

2. Possible inhospital explanations: differences in recognition and management after an MI between patients with COPD and non-COPD patients

Differences in diagnosis and inhospital recognition management are presented in table 2. Patients with COPD who had a STEMI were more likely to have an initial diagnosis other than definite STEMI (OR 1.24, 95\% CI 1.19 to 1.30) or ACS (OR 1.52, 95\% CI 1.42 to 1.62). After a STEMI, patients with COPD were less likely to have pPCI (OR $0.87,95 \%$ CI 0.83 to 0.92 ). There was no evidence that patients with COPD were less likely to receive thrombolysis (OR $0.96,95 \%$ CI 0.91 to 1.10 ).

In adjusted results, differences in time to reperfusion have been expressed in terms of exponentiated linear regression coefficients which, in this case, represent ratios of geometric means. The relationship between COPD and time to reperfusion was found to be different depending on whether diagnosis of MI was delayed ( $p$ value for interaction $<0.001$ ). The median time to reperfusion was $43.7 \mathrm{~min}$ longer for patients with COPD compared with non-COPD patients among those who had a delay in diagnosis (median time to reperfusion $152.9 \mathrm{~min}$ (IQR, 
Figure 1 Study selection.

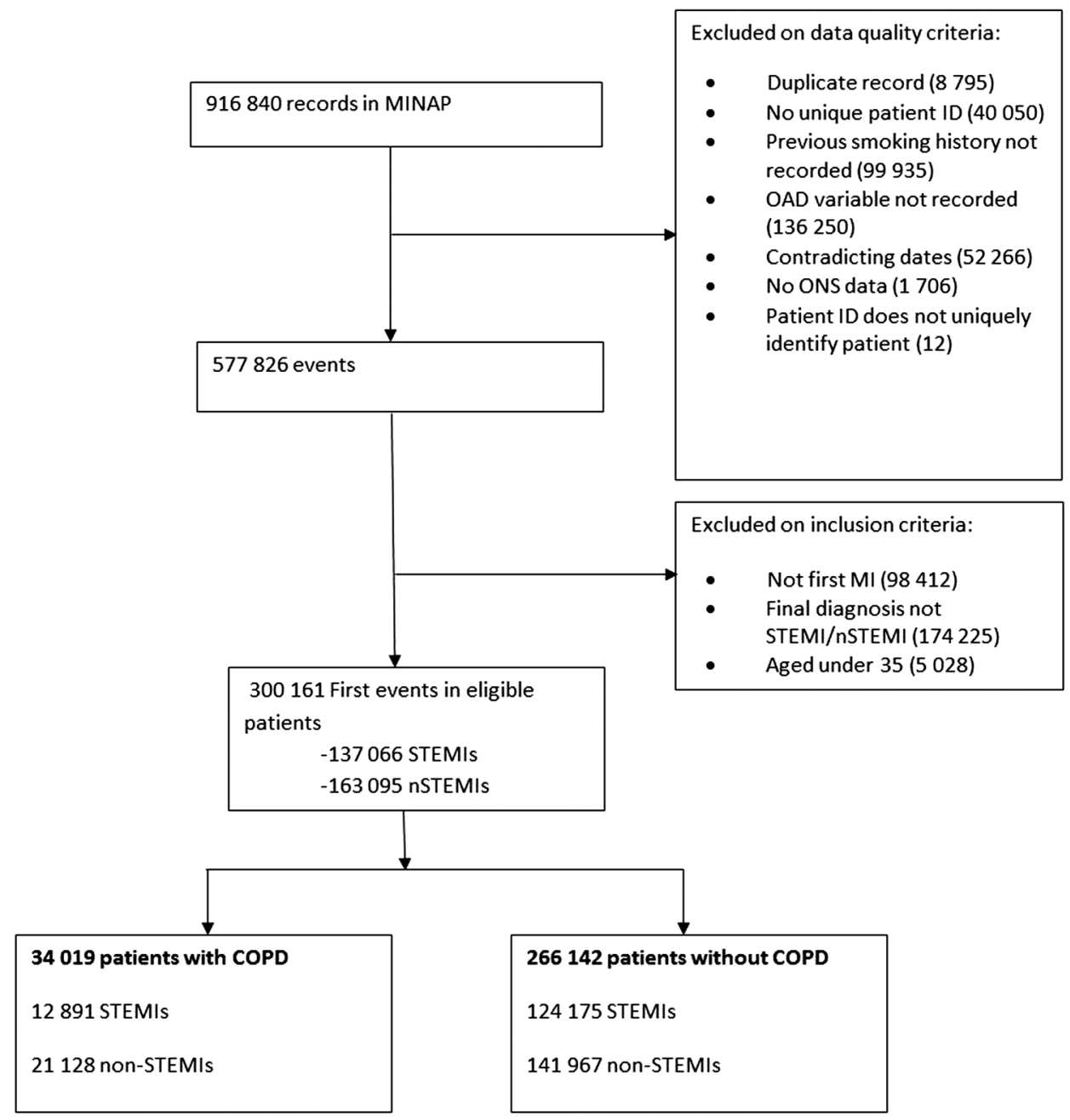

74.3-705.6 $\mathrm{min}$ ) for patients with COPD, and 109.2 $\mathrm{min}$ (IQR, 50.2-260.0 $\mathrm{min}$ ) for non-COPD patients). This difference remained on adjusted analysis and corresponded to $47 \%$ (95\% CI $15 \%$ to $88 \%$ ) longer time to reperfusion for patients with COPD with delayed diagnosis of MI, compared with non-COPD patients with delayed diagnosis of MI. There was no difference in time to reperfusion between patients with COPD and non-COPD patients among those without a delay in diagnosis (see details in online supplementary appendix). Patients with COPD were less likely to receive any of the secondary prevention drugs, apart from thienopyridines, on discharge compared with non-COPD patients, $\beta$ blockers significantly more so than other drugs (OR 0.26 (95\% CI 0.25 to 0.27$)$ ).

3. Accounting for differences in mortality after MI between patients with COPD and non-COPD patients in terms of hospital processes

When compared with the result found in (1), inhospital mortality was reduced after adjusting separately for both diagnostic delay (OR 1.20 (95\% CI 1.06 to 1.36)) and time to reperfusion and use of pPCI (OR 1.11 (95\% CI 0.94 to 1.31 ; table 3)). After adjusting for all inhospital factors, the OR for mortality was 1.13 (95\% CI 0.99 to 1.29 ). For mortality at 180 days, the OR was 1.45 (95\% CI 1.33 to 1.59) after adjusting for age, sex, smoking, calendar year, drugs used on admission and comorbidities, and was 1.45 (95\% CI 1.31 to 1.61) after additionally adjusting for diagnostic delay, use of pPCI and time to reperfusion. Adjusting for use of secondary prevention drugs on discharge substantially reduced ORs for 180 day mortality compared with models only adjusting for inhospital factors (OR 1.25 (95\% CI 1.11 to 1.41$)$ ).

After adjusting for inhospital processes, the estimated attributable risk of inhospital death following a STEMI due to COPD in patients with COPD decreased from $19.4 \%$ (95\% CI 9.1\% to $29.1 \%$ ) to $11.5 \%$ (95\% CI $-1.0 \%$ to $22.4 \%$ ). After adjusting for inhospital processes, the estimated attributable risk for death at 180 days due to COPD in patients with COPD following a STEMI decreased from $31.0 \%$ (95\% CI $24.8 \%$ to $37.1 \%$ ) to $20.0 \%$ (95\% CI $9.9 \%$ to $29.1 \%$ ).

\section{Non-ST-elevation myocardial infarctions}

1. Describing the problem: differences in mortality after MI between patients with COPD and non-COPD patients

After adjusting for age, sex, smoking status, calendar year, comorbidities and drugs on arrival, mortality in patients with COPD was higher than non-COPD patients in hospital (OR 1.34 (95\% CI 1.24 to 1.45$)$ ) and 180 days after discharge (OR 1.56 (95\% CI 1.47 to 1.65$)$ ).

2. Possible inhospital mechanisms: differences in diagnosis and management after an MI between patients with COPD and non-COPD patients

Results from the comparison of treatment and diagnosis after a non-STEMI are presented in table 4. Patients with COPD were more likely to have an initial diagnosis other than ACS after a non-STEMI (OR 1.46 (95\% CI 1.41 to 1.50)). After a non-STEMI, patients with COPD were less likely to receive angiography in hospital (OR 0.69 (95\% CI 0.66 to 0.71 )). 
Table 1 Characteristics of patients in the study

\begin{tabular}{|c|c|c|}
\hline Characteristic & COPD n (\%) & Non-COPD n (\%) \\
\hline \multicolumn{3}{|l|}{ Sex } \\
\hline Male & $21053(61.9)$ & $178611(67.1)$ \\
\hline Female & $12908(37.9)$ & $86504(32.5)$ \\
\hline Missing & $80(0.2)$ & $956(0.36)$ \\
\hline \multicolumn{3}{|l|}{ Age (years) } \\
\hline$<60$ & $7627(22.6)$ & $90557(34.1)$ \\
\hline $60-70$ & $8830(26.0)$ & 62947 (23.7) \\
\hline $71-80$ & $10622(31.3)$ & $61549(23.2)$ \\
\hline$>80$ & $6786(20.0)$ & $50126(18.9)$ \\
\hline Missing & 0 & 0 \\
\hline \multicolumn{3}{|l|}{ Smoking status } \\
\hline Current & $14666(43.2)$ & $90026(34.0)$ \\
\hline Ex & $19244(56.8)$ & $87612(33.0)$ \\
\hline Never & 0 & $87541(33.0)$ \\
\hline Missing & 0 & 0 \\
\hline \multicolumn{3}{|l|}{ Previous Angina } \\
\hline Yes & $7426(21.8)$ & 41417 (15.6) \\
\hline No & $25936(76.2)$ & $223089(83.9)$ \\
\hline Missing & $679(2.0)$ & $1565(0.6)$ \\
\hline \multicolumn{3}{|l|}{ Previous PCI } \\
\hline Yes & $908(2.7)$ & $6622(2.5)$ \\
\hline No & $32082(94.3)$ & $255449(96.0)$ \\
\hline Missing & $1051(3.1)$ & $3916(1.5)$ \\
\hline \multicolumn{3}{|l|}{ Previous CABG } \\
\hline Yes & $786(2.3)$ & $5704(2.1)$ \\
\hline No & $32227(94.7)$ & $256574(96.4)$ \\
\hline Missing & $1028(3.0)$ & 3793 (1.4) \\
\hline \multicolumn{3}{|l|}{ Diabetes } \\
\hline Yes-diet controlled & $1193(3.5)$ & $8322(3.1)$ \\
\hline Yes-oral & $2902(8.5)$ & $21418(8.1)$ \\
\hline Yes-insulin & $1241(3.7)$ & 8986 (3.4) \\
\hline Yes_-insulin and oral & $176(0.5)$ & $1178(0.4)$ \\
\hline No & $28030(82.3)$ & $223040(83.8)$ \\
\hline Missing & $499(1.5)$ & $3127(1.2)$ \\
\hline \multicolumn{3}{|l|}{ Treated for hypertension } \\
\hline Yes & $15304(45.0)$ & $117886(44.3)$ \\
\hline No & $18151(53.3)$ & 146459 (55.1) \\
\hline Missing & $586(1.7)$ & $1726(0.7)$ \\
\hline \multicolumn{3}{|c|}{ Treated for hyperlipidaemia } \\
\hline Yes & $9091(26.7)$ & $73641(27.7)$ \\
\hline No & $23399(68.7)$ & $185043(69.6)$ \\
\hline Missing & $1551(4.6)$ & $7387(2.8)$ \\
\hline \multicolumn{3}{|l|}{ Peripheral vascular disease } \\
\hline Yes & $1962(5.8)$ & $9061(3.4)$ \\
\hline No & $30872(90.7)$ & 253720 (95.4) \\
\hline Missing & 1207 (3.6) & $3290(1.2)$ \\
\hline \multicolumn{3}{|c|}{ Previous cerebrovascular disease } \\
\hline Yes & $2823(8.3)$ & $16829(6.3)$ \\
\hline No & $30354(89.2)$ & $247418(93.0)$ \\
\hline Missing & $864(2.5)$ & $1824(0.7)$ \\
\hline \multicolumn{3}{|l|}{ Heart failure } \\
\hline Yes & $2037(6.0)$ & $7426(2.8)$ \\
\hline No & 31080 (91.3) & 256677 (96.5) \\
\hline Missing & $924(2.71)$ & $1968(0.7)$ \\
\hline \multicolumn{3}{|l|}{ Renal failure } \\
\hline Yes & $1681(4.9)$ & $8428(3.2)$ \\
\hline No & $31452(92.4)$ & $255732(96.1)$ \\
\hline Missing & $908(2.7)$ & $1911(0.7)$ \\
\hline
\end{tabular}

Continued
Table 1 Continued

\begin{tabular}{lcc}
\hline Characteristic & COPD $\mathbf{n}(\%)$ & Non-COPD $\mathbf{n}(\%)$ \\
\hline$\beta$ blocker on arrival & & \\
Yes & $3016(8.9)$ & $44585(16.8)$ \\
No & $23544(69.1)$ & $162876(61.2)$ \\
Missing & $7481(22.0)$ & $58610(22.0)$ \\
ACEi/ARB on arrival & & \\
Yes & $8228(24.2)$ & $57288(21.53)$ \\
No & $18331(53.9)$ & $150036(56.4)$ \\
Missing & $7482(22.0)$ & $58747(22.1)$ \\
Statin on arrival & & \\
Yes & $9446(27.8)$ & $65062(24.5)$ \\
No & $17409(51.1)$ & $144498(54.3)$ \\
$\quad$ Missing & $7186(21.1)$ & $56511(21.2)$ \\
Thienopyridine on arrival & & \\
Yes & $2948(8.7)$ & $23240(8.7)$ \\
No & $22729(66.8)$ & $176548(66.4)$ \\
Missing & $8364(24.6)$ & $66283(24.9)$ \\
Death in hospital & $1561(4.6)$ & $8574(3.2)$ \\
Death at 180 days & $4166(12.8)$ & $19693(7.7)$ \\
(survivors to discharge) & & \\
\hline ACEi, ACE inhibitor; ARB, angiotensin receptor blocker; CABG, coronary artery bypass \\
graft; COPD, chronic obstructive pulmonary disease; PCI, percutaneous coronary \\
intervention.
\end{tabular}

Patients with COPD were less likely to receive any of the secondary prevention drugs on discharge, apart from thienopyridines, compared with non-COPD patients, $\beta$ blockers significantly more so than other secondary prevention drugs (OR 0.25 (95\% CI 0.24 to 0.25$)$ ).

3. Accounting for differences in mortality after MI between patients with COPD and non-COPD patients in terms of hospital processes

When compared with results found in (1), inhospital mortality was reduced after adjusting separately for both delay in diagnosis (OR 1.29 (95\% CI 1.19 to 1.39)) and use of angiography (OR 1.18 (95\% CI 1.09 to 1.29); table 5)). After adjusting for both delay in diagnosis and use of angiography the OR for inhospital mortality was 1.16 (95\% CI 1.07 to 1.26$)$. Inhospital factors also appeared to explain some of the mortality difference after a non-STEMI at 180 days. For mortality at 180 days, the OR was reduced from 1.56 (95\% CI 1.47 to 1.65 ) to 1.37 (95\% CI 1.31 to 1.44$)$. Use of secondary prevention also seemed to explain some of the gap in mortality at 180 days. Compared with the model which only adjusted for inhospital processes, the OR for mortality at 180 days was reduced from 1.37 (95\% CI 1.31 to 1.44 ) to 1.26 (95\% CI 1.17 to 1.35 ).

After adjusting for inhospital processes, the estimated attributable risk for inhospital death following a non-STEMI due to COPD in patients with COPD decreased from 25.4\% (95\% CI $19.4 \%$ to $31.0 \%$ ) to $13.8 \%$ (95\% CI $6.5 \%$ to $21.6 \%$ ). After adjusting for inhospital processes, the estimated attributable risk for death at 180-days due to COPD in patients with COPD following a non-STEMI decreased from 35.9\% (95\% CI 32.0\% to $39.4 \%$ ) to $20.6 \%$ (95\% CI $14.5 \%$ to $25.9 \%$ ).

\section{DISCUSSION}

Summary of main findings

For STEMIs, some of the in inhospital mortality difference between patients with COPD and non-COPD patients may be attributable to delays in diagnosis and use of and increased time to 
Table 2 Differences in recognition and treatment of STEMIs between patients with COPD and non-COPD patients

\begin{tabular}{|c|c|c|c|c|c|}
\hline Inhospital treatment and diagnosis & $\begin{array}{l}\text { COPD } \\
\mathrm{N}(\%)\end{array}$ & $\begin{array}{l}\text { Non-COPD } \\
\mathrm{N}(\%)\end{array}$ & $\begin{array}{l}\text { Unadjusted OR } \\
(95 \% \mathrm{Cl})\end{array}$ & $\begin{array}{l}\text { Minimally adjusted } \\
\text { OR }(95 \% \mathrm{Cl})^{*}\end{array}$ & Adjusted OR $(95 \% \mathrm{Cl}) \dagger$ \\
\hline $\begin{array}{l}\text { Initial diagnosis other than definite } \\
\text { STEMI (for final diagnosis is STEMI) }\end{array}$ & $3080(23.9)$ & $24752(19.9)$ & 1.26 (1.21 to 1.32$)$ & 1.28 (1.23 to 1.34$)$ & 1.24 (1.19 to 1.30$)$ \\
\hline Initial diagnosis other than ACS & $1186(9.2)$ & $7398(6.0)$ & $1.59(1.50$ to 1.71$)$ & $1.68(1.64$ to 1.73$)$ & $1.52(1.42$ to 1.62$)$ \\
\hline Primary PCl & $4108(31.8)$ & $44177(35.6)$ & 0.84 (0.81 to 1.87$)$ & $0.69(0.67$ to 0.71$)$ & $0.87(0.83$ to 0.92$)$ \\
\hline Thrombolysis & 5449 (42.6) & $52414(42.7)$ & 0.99 (0.96 to 1.03$)$ & 1.00 (0.96 to 1.03$)$ & $0.96(0.91$ to 1.10$)$ \\
\hline Time to reperfusion & $\begin{array}{l}\text { COPD } \\
\text { Minutes } \\
\text { (median IQR) }\end{array}$ & $\begin{array}{l}\text { Non-COPD } \\
\text { Minutes } \\
\text { (median IQR) }\end{array}$ & $\begin{array}{l}\text { Unadjusted } \\
\text { exponentiated } \\
\text { regression coefficient } \\
(95 \% \mathrm{Cl})\end{array}$ & $\begin{array}{l}\text { Minimally adjusted } \\
\text { exponentiated regression } \\
\text { coefficient }(95 \% \mathrm{Cl})^{*}\end{array}$ & $\begin{array}{l}\text { Adjusted } \\
\text { exponentiated } \\
\text { regression coefficient } \\
(95 \% \mathrm{Cl}) \dagger\end{array}$ \\
\hline $\begin{array}{l}\text { Time to reperfusion from admission } \\
\text { (overall) }\end{array}$ & $37.1(21.8-67.7)$ & $35.0(21.8-63.4)$ & 1.07 (1.04 to 1.09$)$ & 1.05 (1.03 to 1.07$)$ & 1.04 (1.02 to 1.07$)$ \\
\hline $\begin{array}{l}\text { Time to reperfusion from admission } \\
\text { (initial diagnosis other than STEMI) }\end{array}$ & $152.9(74.3-705.6)$ & $109.2(50.2-260.0)$ & 1.44 (1.24 to 1.67$)$ & 1.35 (1.16 to 1.58$)$ & 1.47 (1.15 to 1.88$)$ \\
\hline $\begin{array}{l}\text { Time to reperfusion from admission } \\
\text { (initial diagnosis STEMI) }\end{array}$ & $35.0(21.8-63.4)$ & $35.0(21.8-61.2)$ & 1.04 (1.01 to 1.06$)$ & 1.03 (1.01 to 1.05$)$ & $1.03(1.00$ to 1.05$)$ \\
\hline Discharge treatment & COPD n (\%) & Non-COPD n (\%) & $\begin{array}{l}\text { Unadjusted } \\
\text { OR }(95 \% \mathrm{Cl})\end{array}$ & $\begin{array}{l}\text { Minimally adjusted } \\
\mathrm{OR}^{*}(95 \% \mathrm{Cl})\end{array}$ & $\begin{array}{l}\text { Adjusted } \\
\text { OR }(95 \% \mathrm{Cl}) \dagger\end{array}$ \\
\hline Discharge on $\beta$ blockers & $5776(44.7)$ & $94784(76.4)$ & $0.25(0.24$ to 0.26$)$ & $0.25(0.24$ to 0.26$)$ & $0.26(0.25$ to 0.27$)$ \\
\hline $\begin{array}{l}\text { Discharge on ACE inhibitor or } \\
\text { angiotensin receptor blocker }\end{array}$ & $9579(74.2)$ & $96508(77.8)$ & 0.83 (0.79 to 0.86$)$ & 0.87 (0.83 to 0.91$)$ & 0.89 (0.85 to 0.93$)$ \\
\hline Discharge on aspirin & $10344(80.1)$ & $102925(82.9)$ & 0.83 (0.79 to 0.87$)$ & 0.87 (0.83 to 0.92$)$ & 0.90 (0.85 to 0.94$)$ \\
\hline Discharge on statin & $10373(80.4)$ & $102785(82.8)$ & 0.85 (0.81 to 0.89$)$ & $0.88(0.84$ to 0.93$)$ & 0.91 (0.86 to 0.95$)$ \\
\hline Discharge on thienopyridine & $7799(60.4)$ & $77543(62.5)$ & 0.91 (0.88 to 0.95$)$ & $0.96(0.92$ to 1.01$)$ & $0.98(0.94$ to 1.03$)$ \\
\hline
\end{tabular}

${ }^{*}$ Adjusted for age, sex smoking status and calendar year.

†Adjusted for age, sex, smoking status, calendar year, drugs on admission and comorbidities.

ACS, acute coronary syndromes; COPD, chronic obstructive pulmonary disease; STEMI, ST-elevation myocardial infarction.

reperfusion. Some of the increased mortality for STEMIs at longer time periods up to 6 months may be attributable to decreased use of secondary prevention medicines, especially $\beta$ blockers, but not inhospital processes. For non-STEMIs, some of the difference in inhospital mortality may be attributable to delays in diagnosis and decreased use of angiography shortly after MI. Some of the increased mortality for non-STEMIs at longer time periods up to 6 months may be attributable to decreased use of secondary prevention medicines, and to inhospital delays in diagnosis and decreased use of angiography in hospital.

\section{Interpretation and comparison with other studies}

Several studies have shown both the increased risk for death following MI for people with COPD and differences in management. These studies specifically showed reduced use of secondary prevention and pPCI after a STEMI in patients with COPD, ${ }^{5} 10^{16-18}$ these findings have been replicated here. This study has also shown that these differences in treatment are possible explanations for some of the mortality gap at the population level for both STEMIs and non-STEMIs. In particular, we were able to make use of the detailed timing variables available in MINAP to investigate differences in time to reperfusion after a STEMI.

For STEMIs, we found that diagnosis of MI is more likely to be delayed for patients with COPD compared with non-COPD patients, and that time to reperfusion is longer after a STEMI. We also showed that the effect of delay in diagnosis of MI on the time to reperfusion was greater in patients with COPD compared with non-COPD patients. Patients with COPD were more likely to have a delay in diagnosis and the effect of this delay in diagnosis in time to reperfusion was more severe for them than non-COPD patients. The reason for the delay in diagnosis of MI in patients with COPD may be because symptoms of MI in patients with COPD may be incorrectly attributed to their COPD rather than an MI.

We found that after a non-STEMI, patients with COPD were less likely to receive angiography in hospital than non-COPD patients, and this explained some of the excess inhospital and

Table 3 Mortality after STEMI

\begin{tabular}{|c|c|c|c|c|c|c|}
\hline & $\begin{array}{l}\text { Adjusted for age, } \\
\text { sex, smoking } \\
\text { status and year } \\
\text { Model } 1\end{array}$ & $\begin{array}{l}\text { Adjusted for } \\
\text { model } 1 \text { variables } \\
\text { and comorbidities } \\
\text { and drugs on arrival } \\
\text { Model } 2\end{array}$ & $\begin{array}{l}\text { Adjusted for models } 1 \\
\text { and } 2 \text { variables } \\
\text { and diagnostic delay } \\
\text { Model } 3\end{array}$ & $\begin{array}{l}\text { Adjusted for models } 1 \\
\text { and } 2 \text { variables and use } \\
\text { of reperfusion and } \\
\text { time to reperfusion } \\
\text { Model } 4\end{array}$ & $\begin{array}{l}\text { Adjusted for } \\
\text { models 1-4 } \\
\text { Model } 5\end{array}$ & $\begin{array}{l}\text { Adjusted for } \\
\text { models 1-4 } \\
\text { variables and } \\
\text { secondary } \\
\text { prevention } \\
\text { Model } 6\end{array}$ \\
\hline & OR $(95 \% \mathrm{Cl})$ & & & & & \\
\hline Inhospital mortality & 1.27 (1.16 to 1.39$)$ & 1.24 (1.10 to 1.41$)$ & $1.20(1.06$ to 1.36$)$ & 1.11 (0.94 to 1.31$)$ & 1.13 (0.99 to 1.29$)$ & - \\
\hline 180-day mortality & $1.43(1.29$ to 1.58$)$ & 1.45 (1.33 to 1.59$)$ & 1.43 (1.32 to 1.54$)$ & 1.46 (1.32 to 1.62$)$ & 1.45 (1.31 to 1.61$)$ & 1.25 (1.11 to 1.41$)$ \\
\hline
\end{tabular}

All Odds ratios compare patients with COPD with non-COPD patients.

COPD, chronic obstructive pulmonary disease; STEMI, ST-elevation myocardial infarction. 
Table 4 Differences in recognition and inhospital treatment of non-STEMIs between patients with COPD and non-COPD patients

\begin{tabular}{|c|c|c|c|c|c|}
\hline & $\begin{array}{l}\text { COPD } \\
\mathrm{N}(\%)\end{array}$ & $\begin{array}{l}\text { Non-COPD } \\
\mathrm{N}(\%)\end{array}$ & $\begin{array}{l}\text { Unadjusted } \\
\text { OR ( } 95 \% \mathrm{Cl})\end{array}$ & $\begin{array}{l}\text { Minimally adjusted } \\
\mathrm{OR}^{*}(95 \% \mathrm{Cl})\end{array}$ & $\begin{array}{l}\text { Adjusted OR } \\
(95 \% \mathrm{Cl}) \dagger\end{array}$ \\
\hline \multicolumn{6}{|l|}{ Inhospital treatment and diagnosis } \\
\hline Initial diagnosis other than $\mathrm{MI}$ & $9551(45.2)$ & $50365(35.5)$ & 1.50 (1.46 to 1.54$)$ & 1.68 (1.64 to 1.73$)$ & $1.46(1.41$ to 1.50$)$ \\
\hline Angiography in hospital & $8629(40.9)$ & $74304(52.2)$ & 0.77 (0.76 to 0.79$)$ & $0.63(0.61$ to 0.65$)$ & 0.69 (0.66 to 0.71$)$ \\
\hline \multicolumn{6}{|l|}{ Discharge treatment } \\
\hline Discharge on $\beta$ blockers & $6632(31.4)$ & $925059(64.9)$ & 0.25 (0.24 to 0.26$)$ & 0.24 (0.23 to 0.25$)$ & 0.25 (0.24 to 0.25$)$ \\
\hline $\begin{array}{l}\text { Discharge on ACE inhibitor } \\
\text { or angiotensin receptor blocker }\end{array}$ & $12762(60.4)$ & $89368(63.0)$ & 0.90 (0.87 to 0.92 ) & 0.91 (0.88 to 0.94 ) & 0.94 (0.91 to 0.97$)$ \\
\hline Discharge on aspirin & $15234(72.1)$ & $106652(75.1)$ & 0.86 (0.83 to 0.88$)$ & 0.88 (0.85 to 0.91$)$ & $0.91(0.88$ to 0.94$)$ \\
\hline Discharge on statin & $15141(71.7)$ & $104804(73.8)$ & 0.90 (0.87 to 0.93 ) & 0.90 (0.87 to 0.93 ) & 0.93 (0.90 to 0.96$)$ \\
\hline Discharge on thienopyridine & $11277(53.4)$ & $78233(55.1)$ & $0.93(0.90$ to 0.96$)$ & 0.95 (0.91 to 0.98$)$ & $0.97(0.94$ to 1.01$)$ \\
\hline
\end{tabular}

*Adjusted for age, sex smoking status and calendar year.†Adjusted for age, sex, smoking status, calendar year, drugs on admission and co-morbidities.

COPD, chronic obstructive pulmonary disease; MI, myocardial infarction; STEMI, ST-elevation myocardial infarction.

180-day mortality. Use of angiography is driven by risk scoring, and patients at moderate and higher risk of death within 6 months should be offered angiography within $96 \mathrm{~h}$ of admission to hospital after a non-STEMI. ${ }^{19}$ It is unclear why, as a population, that although patients with COPD are at a higher risk of mortality they are less likely to receive angiography in hospital.

After both STEMIs and non-STEMIs, patients with COPD were less likely to be prescribed secondary prevention medicines than non-COPD patients. This may only have been to a clinically relevant degree for $\beta$ blockers. It is known that patients with COPD are less likely to be prescribed $\beta$ blockers after an MI, and that prescribing them improves survival. ${ }^{11}$ This study has demonstrated that the increased mortality associated with not prescribing secondary prevention medicines could explain some of the mortality gap up to 6 months at the population level.

We found that recognition of MI in patients with COPD was impaired compared with non-COPD patients. However, all patients included in this analysis were eventually diagnosed with MI. This suggests that patients with COPD may be at higher risk of having a completely missed MI. Indeed, recent work has suggested that as many as 1 in 12 patients admitted to hospital with an exacerbation of COPD meet the criteria for MI, and that this represents underdiagnosis of $\mathrm{MI}$ in patients with COPD. ${ }^{20}$ However, as troponin may also be increased during stable periods of COPD ${ }^{21}$ there is also a potential for overdiagnosis of $\mathrm{MI}$ in people with COPD. Any future intervention which aims to increase recognition of $\mathrm{MI}$ in people with COPD should also investigate the potential effects of overdiagnosis.

\section{Strengths and limitations}

The major strengths of this study were its size, representativeness and level of detail on inhospital management and outcomes. The study included over 300000 people and used data collected from all hospitals in the UK which admit patients for ACS. As secondary prevention treatment is known to be different for patients with COPD compared with non-COPD patients, only using first MIs allowed us to assess the effect of COPD on mortality after an MI without bias due to differences in previous treatment. Another strength of this study was our ability to separate factors which could explain increased inhospital mortality from increased mortality following discharge. If patients with COPD were more likely to die in hospital, as we found, the reasons that they did not receive certain treatments may have been because they were more likely to die before they received these treatments compared with non-COPD patients. In order to avoid this bias, for mortality at 180 days, we only analysed data for those who had survived until at least discharge. This also allowed the potential contribution of secondary prevention to the mortality gap to be investigated.

One of the limitations of this study is potential misclassification of COPD status. The strategy used to identify may have misclassified asthmatic smokers as patients with COPD, and may have misclassified patients with COPD as non-COPD patients. However, the prevalence of COPD in our study is similar to that of previous work in similar settings. 5101622 The presence of asthmatics in our COPD group and patients with COPD in the non-COPD group is likely to have biased our findings towards the null. However, this would not change our findings. In addition, a sensitivity analysis, which compared mortality for asthmatic patients compared with non-asthmatic patients found that mortality was not increased in the asthmatic group (see online supplementary material). One of the limitations of using an audit database such as MINAP is the lack of available data which would not have been collected at hospital admission. Ideally, information on COPD severity and cause of death would have been collected. In addition, ideally information on socioeconomic status would have been available as this is a

Table 5 Mortality after non-STEMI. All ORs compare patients with COPD with non-COPD patients

\begin{tabular}{|c|c|c|c|c|c|c|}
\hline & $\begin{array}{l}\text { Adjusted for age, } \\
\text { sex, smoking status } \\
\text { and year } \\
\text { Model } 1\end{array}$ & $\begin{array}{l}\text { Adjusted for model } 1 \\
\text { variables and } \\
\text { comorbidities and } \\
\text { drugs on arrival } \\
\text { Model } 2\end{array}$ & $\begin{array}{l}\text { Adjusted for models } \\
1 \text { and } 2 \text { variables } \\
\text { and diagnostic } \\
\text { delay } \\
\text { Model } 3\end{array}$ & $\begin{array}{l}\text { Adjusted for models } \\
1 \text { and } 2 \text { variables } \\
\text { and use of } \\
\text { angiography in } \\
\text { hospital } \\
\text { Model } 4\end{array}$ & $\begin{array}{l}\text { Adjusted for } \\
\text { models } 1-4 \\
\text { variables } \\
\text { Model } 5\end{array}$ & $\begin{array}{l}\text { Adjusted for models } \\
1-4 \text { variables and } \\
\text { secondary } \\
\text { prevention } \\
\text { Model } 6\end{array}$ \\
\hline & OR (95\% Cl) & & & & & \\
\hline Inhospital mortality & 1.40 (1.30 to 1.52$)$ & 1.34 (1.24 to 1.45$)$ & 1.29 (1.19 to 1.39$)$ & 1.18 (1.09 to 1.29$)$ & 1.16 (1.07 to 1.26$)$ & - \\
\hline 180-day mortality & 1.63 (1.56 to 1.70$)$ & 1.56 (1.47 to 1.65$)$ & 1.45 (1.38 to 1.52$)$ & 1.43 (1.34 to 1.50$)$ & 1.37 (1.31 to 1.44$)$ & 1.26 (1.17 to 1.35$)$ \\
\hline
\end{tabular}


potential confounder for the relationship between COPD and mortality after MI. Future studies should investigate the relationship between COPD severity and explanations for the mortality gap in patients with COPD after MI and cause of death in patients with COPD following MI.

\section{Conclusions}

Patients with COPD appear to receive poorer treatment after an MI compared with non-COPD patients. These differences in recognition and treatment of MI seem to explain some of the mortality gap between patients with COPD and non-COPD patients both inhospital and at 6 months postdischarge. Delayed diagnosis, timing and use of reperfusion of a STEMI, use of angiography after a non-STEMI and use of secondary prevention medicines are all potential explanations for the mortality gap after MI in people with COPD.

\section{Key messages}

\section{What is already known on this subject?}

People with chronic obstructive pulmonary disease (COPD) have both a higher risk for myocardial infarction (MI) and poorer long-term outcomes following MI. Previous studies have also shown that patients with COPD are less likely to receive $\beta$ blockers on discharge after an $\mathrm{MI}$ and are less likely to receive $\mathrm{PCl}$ after an ST-elevation myocardial infarction (STEMI). Findings for differences in inhospital mortality have been mixed, with some studies finding higher mortality for patients with COPD and some studies finding no difference. The heterogeneity in findings may be due to differences in treatment practices. The extent to which differences in treatment can explain differences in mortality at the population level, the 'mortality gap', is unclear.

\section{What might this study add?}

This study aimed to determine whether differences in inhospital treatment and discharge between patients with and without COPD could explain all or some of the difference in mortality for both inhospital and at 180 days postdischarge at the population level. We found that delayed diagnosis of $\mathrm{Ml}$, decreased use of reperfusion and increased time to reperfusion after a STEMI, decreased use of angiography after a non-STEMI and decreased use of secondary prevention medicines might all explain some of the mortality gap for people with COPD after an MI.

\section{How might this impact on clinical practice?}

We have found that differences in potentially modifiable inhospital processes may explain some of the mortality gap between patients with and without COPD after an MI. Clinicians need to be aware that it may be easier to miss Mls in people with COPD and may need to be aware of more unusual presentations of $\mathrm{MI}$ in people with COPD. In addition, our results suggest that patients with COPD may benefit from more aggressive treatment after an MI.

\section{Author affiliations}

Faculty of Epidemiology and Population Health, London School of Hygiene and Tropical Medicine, London, UK

${ }^{2}$ Farr Institute of Health Informatics Research, London, UK

${ }^{3}$ Department of Epidemiology and Public Health, University College London, London, UK

${ }^{4}$ National Heart and Lung Institute, Imperial College London, London, UK ${ }^{5}$ Barts NIHR Biomedical Research Unit, Queen Mary University of London, London, UK
}

Correction notice This paper has been updated since it appeared online and in print to reflect the correct open access licence of CC-BY.

Contributors JKQ, LS, HH, AT and JW: Conceived of the study. KJR, LS and JKQ: Designed the study. KJR and JKQ: Analysed data. KJR: Wrote first draft. All authors: Interpreted the results, critically revised drafts and approved the final version.

Funding JKQ is supported by an MRC Population Health Scientist fellowship [G0902135] which funded this work. LS is supported by a Wellcome Trust Senior Research Fellowship in Clinical Science [098504/Z/12/Z]. HH is supported by the National Institute for Health Research [RP-PG-0407-10314], the Wellcome Trust [WT 086091/Z/08/Z], and the Medical Research Council Prognosis Research Strategy Partnership [G0902393/99558] and by awards to establish the Farr Institute of Health Informatics Research, London, from the Medical Research Council, Arthritis Research UK, British Heart Foundation, Cancer Research UK, Chief Scientist Office, Economic and Social Research Council, Engineering and Physical Sciences Research Council, National Institute for Health Research, National Institute for Social Care and Health Research, and Wellcome Trust. JW is supported by an NIHR Applied Programme Grant [RP-PG-0109-10056] and by the MRC COPD MAP programme. AT is supported by Barts and The London NIHR Cardiovascular Biomedical Research Unit, which is funded by the NIHR.

\section{Competing interests None.}

Ethics approval London School of Hygiene and Tropical Medicine Research Ethics Committee \& MINAP Academic Group.

Provenance and peer review Not commissioned; externally peer reviewed.

Data sharing statement This study used data from the Myocardial Ischaemia National Audit Project (MINAP) database. MINAP data are available for research purposes from the National Institute for Cardiovascular Outcomes Research upon application to the MINAP Academic Group.

Open Access This is an Open Access article distributed in accordance with the terms of the Creative Commons Attribution (CC BY 4.0) license, which permits others to distribute, remix, adapt and build upon this work, for commercial use, provided the original work is properly cited. See: http://creativecommons.org/ licenses/by/4.0/

\section{REFERENCES}

1 Schneider C, Bothner U, Jick SS, et al. Chronic obstructive pulmonary disease and the risk of cardiovascular diseases. Eur J Epidemiol 2010;25:253-60.

2 Feary JR, Rodrigues LC, Smith CJ, et al. Prevalence of major comorbidities in subjects with COPD and incidence of myocardial infarction and stroke: a comprehensive analysis using data from primary care. Thorax 2010;65:956-62.

3 Enriquez JR, de Lemos JA, Parikh SV, et al. Association of chronic lung disease with treatments and outcomes patients with acute myocardial infarction. Am Heart J 2013;165:43-9.

4 Dziewierz A, Siudak Z, Rakowski T, et al. Relationship between chronic obstructive pulmonary disease and in-hospital management and outcomes in patients with acute myocardial infarction. Kardiol Pol 2010;68:294-301.

5 Andell P, Koul S, Martinsson A, et al. Impact of chronic obstructive pulmonary disease on morbidity and mortality after myocardial infarction. Open Heart 2014;1: e000002.

6 Stefan MS, Bannuru RR, Lessard D, et al. The impact of COPD on management and outcomes of patients hospitalized with acute myocardial infarction: a 10-year retrospective observational study. Chest 2012;141:1441-8.

7 Lozano R, Naghavi M, Foreman K, et al. Global and regional mortality from 235 causes of death for 20 age groups in 1990 and 2010: a systematic analysis for the Global Burden of Disease Study 2010. Lancet 2012:380:2095-128.

8 Sin DD, Anthonisen NR, Soriano JB, et al. Mortality in COPD: Role of comorbidities. Eur Respir J 2006;28:1245-57

9 Setoguchi S, Glynn RJ, Avorn J, et al. Improvements in Long-Term Mortality After Myocardial Infarction and Increased Use of Cardiovascular Drugs After Discharge A 10-Year Trend Analysis. J Am Coll Cardiol 2008;51:1247-54

10 Stefan M, Bannuru R, Lessard D, et al. The impact of COPD on management and outcomes of patients hospitalized with acute myocardial infarction; a ten-year retrospective observational study. J Hosp Med 2012;7:S64-S5.

11 Quint JK, Herrett E, Bhaskaran $\mathrm{K}$, et al. Effect of beta blockers on mortality after myocardial infarction in adults with COPD: population based cohort study of UK electronic healthcare records. BMJ 2013;347:f6650.

12 Herrett E, Smeeth L, Walker L, et al. The Myocardial Ischaemia National Audit Project (MINAP). Heart 2010;96:1264-7.

13 CPRD. Available from: www.cprd.com.

14 Denaxas SC, George J, Herrett E, et al. Data resource profile: cardiovascular disease research using linked bespoke studies and electronic health records (CALIBER). Int J Epidemiol 2012;41:1625-38. 
15 Cattle BA, Baxter PD, Greenwood DC, et al. Multiple imputation for completion of a national clinical audit dataset. Stat Med 2011;30:2736-53.

16 Bursi F, Vassallo R, Weston SA, et al. Chronic obstructive pulmonary disease after myocardial infarction in the community. Am Heart J 2010;160:95-101.

17 Rha SW, Li YJ, Chen KY, et al. Impact of chronic obstructive pulmonary disease on the clinical characteristics and outcomes in propensity-matched patients with acute myocardial infarction. Am J Cardiol 2009;103(9):36B-7B.

18 Salisbury AC, Reid KJ, Spertus JA. Impact of chronic obstructive pulmonary disease on post-myocardial infarction outcomes. Am J Cardiol 2007;99:636-41.
19 NICE. Unstable angina and NSTEMI (2013 update). 2010.

20 McAllister DA, Maclay JD, Mills NL, et al. Diagnosis of myocardial infarction following hospitalisation for exacerbation of COPD. Eur Respir J 2012;39:1097-103.

21 Neukamm AMC, Hoiseth AD, Hagve TA, et al. High-sensitivity cardiac troponin $T$ levels are increased in stable COPD. Heart 2013;99:382-7.

22 Hadi HA, Zubaid M, Al Mahmeed W, et al. Prevalence and prognosis of chronic obstructive pulmonary disease among 8167 Middle Eastern patients with acute coronary syndrome in the current era. Circulation 2010;122:E48. 